\title{
PLURALIZANDO A GOVERNANÇA PELA PERSPECTIVA DO NEXO ÁGUA-ENERGIA-ALIMENTOS: CAMINHOS PARA A SUSTENTABILIDADE NA MACROMETRÓPOLE PAULISTA ${ }^{1}$
}

\author{
Alberto Matenhauer URBINATTI² \\ Leandro Luiz GIATTI ${ }^{3}$
}

RESUMO: A governança da água, da energia e dos alimentos no contexto da Macrometrópole paulista, a partir do conceito de "nexo", pode ser reconhecida como interdependente e muito desafiadora por conta dos inúmeros trade-offs e sinergias entre os recursos. Todavia, é possível dizer que esses recursos foram historicamente governados de forma separada, pois há uma tendência clara de especialização do conhecimento nas decisões. O objetivo deste artigo é discutir de forma crítica possíveis nexos entre a governança da água, energia e alimentos no contexto da Macrometrópole paulista. A metodologia se divide em dois momentos: primeiro uma revisão bibliográfica narrativa, na qual apresentamos as principais ideias presentes no conceito de governança do nexo e sugerimos repensá-lo a partir de um olhar mais plural sobre a governança dado pela abordagem de caminhos para a sustentabilidade (pathways to Sustainability); segundo, uma análise de conteúdo da Carteira de Projetos do Plano de Ação para a

\footnotetext{
1 Artigo produzido no âmbito do Projeto Temático FAPESP 2015/03804-9 "Governança Ambiental na Macrometrópole Paulista Face à Variabilidade Climática”. Agradecimentos ao CNPq por meio do Processo 3098402018-0.

2 Universidade de São Paulo (USP), São Paulo - SP - Brasil. Sociólogo e doutor em Saúde Pública. Universidade Estadual de Campinas (Unicamp), Campinas - SP - Brasil. Pós-doutorando em Estudos Sociais da Ciência e Tecnologia. ORCID: https://orcid.org/0000-0002-8257-0167. albertourbinatti@gmail.com.

3 Universidade de São Paulo (USP), São Paulo - SP - Brasil. Biólogo e doutor em Saúde Pública. Professor associado da Faculdade de Saúde Pública. Editor adjunto da revista Ambiente \& Sociedade e pesquisador no grupo Meio Ambiente e Sociedade do Instituto de Estudos Avançados da USP. ORCID: https://orcid.org/0000-0003-11546503.1giatti@usp.br.
} 
Macrometrópole Paulista 2013-2040 (PAM) a partir de cinco eixos: entidades políticas e espaços, estruturação e prática poder e conhecimento, lidar com a incerteza e história política, cultura e contexto. Os resultados indicam que o PAM traz perspectivas amigáveis ao nexo marcadas por aspectos estratégicos e técnicos, não considerando de maneira mais aprofundada experiências humanas de atores mais vulneráveis em relação ao acesso aos recursos no contexto macrometropolitano.

PALAVRAS-CHAVE: nexo água-energia-alimento; governança do nexo; governança sustentável; Macrometrópole paulista

\title{
PLURALIZING GOVERNANCE FROM THE PERSPECTIVE OF THE WATER-ENERGY-FOOD NEXUS: PATHWAYS TO SUSTAINABILITY IN THE MACRO METROPOLIS OF SÃO PAULO
}

\begin{abstract}
Based on the concept of "nexus," the governance of water, energy, and food in the context of the Macro metropolis of São Paulo can be recognized as interdependent and very challenging in terms of trade-offs and synergies among resources. However, these resources have historically been governed separately, as there is a clear tendency for knowledge specialization in decisions. This article aims to critically discuss the "nexuses" between the governance of water, energy, and food in the context of the Macro metropolis of São Paulo. The methodology is divided into two moments. First, a narrative literature review, in which we present the concept of nexus governance and suggest rethinking it from a more plural perspective on governance given by the pathways to Sustainability approach. Second, a content analysis of the Project Portfolio of the Action Plan for the Macro metropolis of São Paulo 2013-2040 (PAM, in Portuguese) from five axes: political entities and spaces, structures and practice, power and knowledge, dealing with uncertainty, and political history, culture and context. The results indicate that PAM brings nexus-friendly perspectives marked by strategic and technical aspects, failing in considering more deeply human experiences of vulnerable actors in terms of access to resources in the context of a Macro metropolis.
\end{abstract}

KEYWORDS: water-energy-food nexus; governance of the nexus; Sustainability governance; Macro metropolis of São Paulo

\section{Introdução}

Em diferentes áreas de estudo, tais como engenharia, economia e estudos ambientais e urbanos sobre as mudanças políticas e ambientais globais, a noção 
de haver um "nexo" entre água, energia e alimentos tem ganhado destaque nos últimos anos. $\mathrm{O}$ núcleo desta ideia compreende profundas interligaçóes entre os sistemas de abastecimento de água, energia e alimentos, todos sujeitos a pressóes radicalmente crescentes da expansão da população e do consumo de materiais e recursos (COVARRUBIAS, 2019). Por exemplo, compreender a demanda de água na geração de energias renováveis (como biocombustíveis) ou o gasto de energia no uso de fertilizantes em uma determinada plantaçáo estão dentro de uma chamada "racionalidade do nexo" (GIATTI, 2019; BENITES-LAZARO et al., 2020).

Ao mesmo tempo em que esta racionalidade já está presente em muitas das infraestruturas existentes em nosso planeta, ela aparece também como busca por decisóes inovadoras em termos ambientais. Em geral, diversos autores concordam que o nexo é definido pela busca de soluçôes mais viáveis para o planeta em meio a cenários de desigualdades, escassez, má distribuição e mau uso dos recursos naturais, tudo isso permeado pelas exacerbaçóes e incertezas associadas às mudanças globais (ALLOUCHE; MIDDLETON; GYAWALI, 2015; RASUL; SHARMA, 2016; GIATTI et al., 2019).

Neste sentido, apesar dos cenários de incertezas ambientais globais, a inter-relação com cenários contextuais também faz muito sentido. Os recursos escassos de que tratamos são, ao mesmo tempo, globais e locais. Portanto, a racionalidade do nexo teria alguma dimensão do que é conhecido como "glocal", isto é, os processos de globalização que não apagam as diferenças contextuais e locais (KHONDKER, 2004). Nâo obstante, esta característica sugere que o conceito de nexo exige alguma flexibilidade para ser compreendido por seus aspectos, digamos, socialmente construídos em termos menos normativos.

Este artigo assume a hipótese de que a racionalidade do nexo água-energia-alimentos ganharia novos contornos ao ser menos pautada por aspectos tecnicistas e, portanto, mais plural e aberta às incertezas para que possa ser ressignificada a partir de especificidades.

\section{Metodologia}

Para elaboração deste trabalho, utilizamos pesquisa bibliográfica a partir de metodologia qualitativa. Segundo Alves (1992), a revisão bibliográfica deve servir para contextualizar o problema dentro da área de estudo e para a análise do referencial teórico. Dessa forma, em primeiro lugar, revisaremos de maneira crítica as narrativas principais que aparecem na literatura sobre a governança do nexo. 
Em segundo lugar, propomos aproximar a perspectiva de governança do nexo com o conceito de caminhos para a sustentabilidade (CPS) proposto por Leach et al. (2007) e Leach, Scoones e Stirling (2007, 2010), a fim de analisá-la a partir de um olhar construtivista proposto pelo conceito.

Por fim, apresentaremos uma análise de conteúdo da Carteira de Projetos do Plano de Ação para a Macrometrópole Paulista 2013-2040 (PAM), buscando problematizar e identificar potencialidades e aspectos de uma governança do nexo entre água, energia e alimentos no contexto da Macrometrópole paulista.

\section{Governança do nexo água-energia-alimento}

As interações que o conceito de nexo propóe vêm acompanhadas de dois aspectos contrastantes em processos de governança. O primeiro deles é o de trade-offs (entendido aqui como a condição de que soluçóes de um setor geram consequências para outros setores), enquanto o segundo é o de sinergias (situaçóes que geram resultados positivos para diferentes setores). Segundo Kurian et al. (2018), se por um lado a análise dos trade-offs tem o potencial de revelar quais as prioridades em um processo de governança e informar as normas de equidade definidas localmente nas intervençóes, por outro, compreender as sinergias pode determinar o progresso na garantia de um equilíbrio e mitigação de possíveis efeitos reversos em planejamento e gestão ambiental. Em última análise, os dois aspectos envolvem negociaçôes (KURIAN, 2017).

Estes aspectos estão inseridos em um uma proposta que clama pela ideia de "dissolução dos silos" (break down the silos) (ARTIOLI; ACUTO; McARTHUR, 2017). Em outras palavras, trata-se do argumento de que é preciso considerar processos decisórios transescalares, transsetoriais e transdisciplinares. Isto pode ser entendido como uma forma de buscar abrir as caixas da especialização. No entanto, ao abrir essas caixas, o conceito não deixa claro de que forma o conhecimento deve ser integrado (CAIRNS; KRZYWOSZYNSKA, 2016). Da mesma forma, os perigos que estão presentes em novos silos transversais não ficam evidentes (STIRLING, 2015).

Por ser um conceito relativamente novo, a chamada "governança do nexo" tem aparecido frequentemente na literatura global. Urbinatti et al. (2020a), ao revisar sistematicamente a literatura sobre a questão, concluíram que o centralismo da água, a ideia de sistemas, a integração política, o desenvolvimento sustentável, a governança ambiental, o gerenciamento socioeconômico, a segurança dos recursos e as mudanças climáticas são os principais temas de pesquisa que aparecem por trás do uso do conceito. Mais do que isso, estes temas podem 
ser agrupados a partir de conceitos de governança anteriores, tais como: governança da água e das bacias hidrográficas, governança ambiental e dos sistemas, governança do risco e dos recursos, governança econômica, governança global, governança urbana, governança integrativa e cooperativa, e finalmente governança "epistêmica" e transdisciplinar. Em outras palavras, o estudo permitiu concluir que o conceito de governança do nexo nasce a partir de outras perspectivas mais sólidas já presentes na literatura.

Dalla Fontana et al. (2020) estudaram de forma crítica artigos sobre nexo que têm sido produzidos em instituiçóes brasileiras ou a partir de estudos de caso referentes ao Brasil. Os autores selecionaram e analisaram 46 estudos. A partir deles, compreenderam que uma das categorias macro de palavras-chave foi "governança e política", constituída por 11 outras palavras-chave. Por um lado, este é um dado importante, pois ela aparece em quarto lugar, depois de "água" (53 palavras-chave relacionadas), "energia" (43) e "nexo" (27). Por outro lado, utilizar as palavras-chave "governança e política" não são garantias de um debate mais aprofundado em torno dos próprios significados da governança do nexo enquanto conceito. Além disso, os resultados encontrados confirmam uma predominância das ciências naturais, das engenharias e da economia, principalmente com base em estudos quantitativos, enquanto as ciências sociais ainda pouco exploram o tema.

Um exemplo de um olhar, digamos, mais "social" para o nexo aparece em Giatti et al. (2019) que, ao discutirem os desafios e oportunidades para a Região Metropolitana de São Paulo, reforçam que fatores como a urbanização, igualdade e inclusão social, em processos de governança horizontal e vertical, devem ser considerados. Outro exemplo está em Urbinatti et al. (2020b), no qual é sugerida uma abordagem mais flexível para a governança do nexo a partir do conceito de "tecnologias da humildade" de Sheila Jasanoff (2003). Com isso, é possível conceber que a racionalidade do nexo pode ser promovida por meio de processos participativos em dinâmicas de laboratórios vivos, contribuindo para a interlocução com tomadores de decisão na busca de integração dentre estratégias de gestão local ou regional (WAHL; NESS; WAMSLER, 2021). Estes tipos de perspectivas se alinham com o que pretendemos neste artigo. É nesse sentido que a partir do tópico seguinte mostraremos como pensar a governança do nexo a partir dos CPS pode ser próspera. 


\section{O nexo a partir da perspectiva de caminhos para a sustentabilidade (CPS)}

Governar os setores de água, energia e alimentos de forma separada exige inúmeros esforços e capacidades de gestão. $\mathrm{O}$ desafio pode ser muito maior quando os setores são pensados de maneira interligada. Exatamente por isso, o próprio olhar para a governança deve ter alguma amplitude que tenha por garantia mais flexibilidade nas definiçóes. É neste sentido que a ideia de caminhos para a sustentabilidade (pathways to Sustainability) pode agregar ao debate sobre o nexo. Esta é uma abordagem que vem sendo encorajada pelo STEPS Centre (Social, Technological and Environmental Pathways to Sustainability), da Universidade de Sussex, Reino Unido. A abordagem parte do pressuposto de que pensar a governança sustentável passa por reconhecer a dinâmica do mundo em que vivemos, a partir das complexas relaçóes entre ecologia, tecnologia, pobreza e justiça (LEACH; SCOONES; STIRLING, 2007).

Isto leva a um olhar sistêmico para sistemas biológicos, sociais, econômicos ou políticos, e particularmente em suas interaçóes. Estes sistemas dinâmicos seriam caracterizados pela complexidade, incerteza, não-equilíbrio e muitas vezes pela caoticidade. Neste contexto, o reconhecimento de um "estado permanente de incertezas" (incertitude status) (STIRLING, 2010) é importante para que não reduzamos as complexidades a meros cálculos, ou em outras palavras, pressóes por justificação (COLLINGRIDGE, 1980). Estas "pressóes” políticas, econômicas e disciplinares para justificação forçam sistematicamente cientistas e formuladores de políticas a enfatizar as condiçóes aparentemente mais traiçoeiras do risco. Contudo, as definiçóes mais convencionais de "risco", como magnitudes ponderadas pela probabilidade, implicam intrinsecamente três outras condiçóes distintas: incerteza (falta de confiança nas probabilidades), ambiguidade (falta de concordância com as magnitudes) e ignorância - onde "não sabemos o que não sabemos" (WYNNE, 1992).

É para lidar com este estado de incertezas que a primeira dimensão sugerida pela CPS é justamente o enquadramento de um determinado sistema e seu ambiente, como ele é delimitado e quais estruturas e funçôes podem ser consideradas essenciais. Assim, o enquadramento e as narrativas múltiplas coexistem, realizadas por diferentes atores e coproduzidas com instituiçóes baseadas no poder e no conhecimento. A abordagem, neste contexto, se expressa entre um olhar sobre os framings, que seria um ponto de vista mais construtivista, e sobre as realidades objetivas, que seriam mais positivistas. 
Figura 1 - Perspectiva de sistemas complexos sugerida pela abordagem CPS

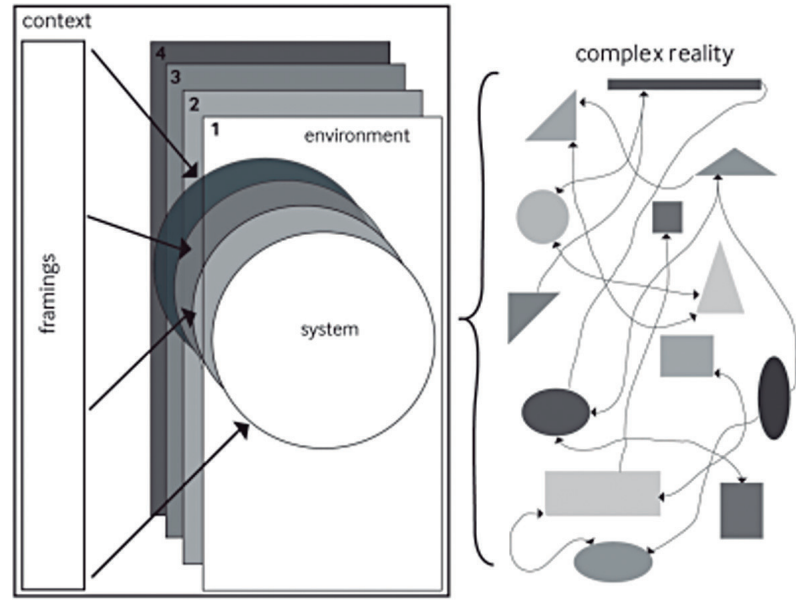

Fonte: Leach, Scoones e Stirling (2007, p.5).

A partir da figura 1, conseguimos observar de forma mais evidente que pensar o nexo a partir dos CPS é entender que a existência de uma série de camadas sobrepostas na governança integrada de recursos. Poderíamos considerar como sistemas a governança da água, da energia e dos alimentos. Estes sistemas, por sua vez, estáo dispostos em determinados ambientes e estáo sendo considerados a partir de enquadramentos contextuais. De alguma maneira, estas camadas ajudam a compreender a realidade em sua complexidade natural.

Além disso, a abordagem CPS sugere que é a governança que moldará os enquadramentos predominantes e a forma como eles serão negociados, colocando as propriedades de um sistema em escalas temporais. É daí que surge no horizonte a sustentabilidade, entendida como a capacidade de manter um certo ritmo através da sua estabilidade, durabilidade, resiliência e robustez (LEACH; SCOONES; STIRLING, 2007). Não obstante, é necessário entender o que significa "sustentabilidade" em um determinado contexto, uma tarefa que a própria governança deve realizar (LEACH et al., 2007).

Esta tarefa é um processo político para a abordagem e, para tal, deve incluir uma diversidade de conhecimentos e relaçóes de poder que surgem nessas interaçóes. Em geral, a consciência das relaçóes de poder na formulação do conhecimento e no processo decisório estimularia o que os autores chamam de "modéstia" na governança (LEACH; SCOONES; STIRLING, 2010). Neste contexto, sugerimos aqui que a governança do nexo, ao englobar olhares para estruturas pré-existentes e propostas futuras de governança integrativa, pode se 
tornar menos normativa e mais "modesta" caso seja pautada nas cinco dimensóes da governança ressaltadas pela abordagem CPS. São elas: entidades políticas e espaços; estruturação e prática; poder e conhecimento; lidar com a incerteza; história, politica e contexto. Na próxima seção, aprofundaremos quais são elas sugerindo insights para o contexto da Macrometrópole paulista (MMP).

\section{Insights para pensar os nexos na Macrometrópole paulista}

A MMP engloba a Região Metropolitana de São Paulo (RMSP), Região Metropolitana da Baixada Santista (RMBS), Região Metropolitana de Campinas (RMC), Região Metropolitana do Vale do Paraíba (RMVP) e a Região Metropolitana do Litoral Norte (RMLN), além das aglomeraçóes urbanas de Sorocaba, Piracicaba e Jundiaí e ainda duas microrregióes (JACOBI; CIBIM; LEAO, 2015). A partir da tendência global de alargamento para além dos seus limites originais, estas grandes regiôes urbanas se tornaram sistemas complexos e interdependentes de questóes sociais, econômicas, ambientais e políticas (LEICHENKO; SOLECKI, 2013). A intensificação das perturbações climáticas aumenta as incertezas da governança ambiental de uma região complexa como a MMP.

A grave fragmentação e inércia nos processos políticos brasileiros ressoam com os interesses arraigados em torno de infraestruturas já estabelecidas, atrasando ainda mais a implementação de transformações sociais e tecnológicas que prometem ambientes mais sustentáveis econômica, ambiental e socialmente (URBINATTI; FERREIRA, 2019). Estas transformaçóes envolvem assimetrias de poder entre grupos com interesses diversos, o que tornaria o processo de governança urbana permeado por questóes de injustiça e de conflitos ambientais (TORRES; RAMOS; GONÇALVES, 2019). A questão hídrica, por exemplo, é notadamente interdependente e condicionante de constantes disputas. Dentro de um escopo de governança em que o poder decisório se caracteriza por uma forte pauta acerca dos recursos hídricos, nota-se que aspectos de racionalidades técnicas se exacerbam, na maioria das vezes voltada ao equacionamento por meio de grandes obras e constante busca por água em locais distantes.

O problema é que são notadas desigualdades consideráveis em termos de índice de desenvolvimento humano entre municípios que fornecem recursos para suprir a necessidade de outros que precisam deles no contexto macrometropolitano (AMARAL et al., 2021). Ou seja, aqueles que fornecem costumam ter índices inferiores aos que recebem, demonstrando que existem injustiças no processo. Há um evidente fator econômico presente em negociaçóes deste tipo. 
De acordo com Torres, Ramos e Pollachi (2020), a MMP é reescalonada para reterritorializaçáo do capital, processo que é fundamental para a compreensáo do próprio desenvolvimento desigual no território que a compóe. A racionalidade econômica é também bastante motivadora de muitos estudos sobre o nexo, o que o torna passível de crítica por muitas vezes estar inserido numa agenda neoliberal (WEITZ et al., 2017).

É justamente para ir além desse fio condutor político-econômico do território que os insights que pretendemos sugerir aqui podem colaborar. Este enquadramento é uma forma de pensar a MMP, a partir da governança da água, energia, alimentos e o meio ambiente, como processos dinâmicos e sistêmicos que se alteram ao longo do tempo. É uma forma de observar trajetórias de mudança, seus precedentes históricos, e os cenários futuros para compreender até que ponto a sustentabilidade está sendo alcançada (LEACH; SCOONES; STIRLING, 2007).

O Quadro 1 sintetiza as sugestóes a partir da abordagem de CPS para pensar a governança do nexo na MMP.

Quadro 1 - Governança do nexo a partir de insights da abordagem CPS para a MMP

\begin{tabular}{|l|l|}
\hline \multicolumn{1}{|c|}{ Eixo } & \multicolumn{1}{c|}{ O que é } \\
\hline $\begin{array}{l}\text { Entidades politicas } \\
\text { e espaços }\end{array}$ & $\begin{array}{l}\text { Reconhecer o significado de múltiplos atores, redes, entidades e espaços, } \\
\text { formais e informais, fixos ou transitórios, em diferentes escalas da MMP } \\
\text { relacionados à água, energia, alimentos e meio ambiente. }\end{array}$ \\
\hline $\begin{array}{l}\text { Estruturação e } \\
\text { prática }\end{array}$ & $\begin{array}{l}\text { Reconhecer a importância de estruturas institucionais duradouras no ter- } \\
\text { ritório, ainda que dispersas, e também o agenciamento dos cidadãos, téc- } \\
\text { nicos e atores políticos para compreender as formas como as relaçóes são } \\
\text { construídas e renegociadas através da prática na governança dos recursos. }\end{array}$ \\
\hline $\begin{array}{l}\text { Poder e } \\
\text { conhecimento }\end{array}$ & $\begin{array}{l}\text { Analisar o significado da economia política para se aprofundar nas for- } \\
\text { mas dispersas e capilares de poder e injustiças ambientais e climáticas, } \\
\text { inclusive dentro da própria geraçáo de conhecimento sobre a MMP. }\end{array}$ \\
\hline $\begin{array}{l}\text { Lidar com a } \\
\text { incerteza }\end{array}$ & $\begin{array}{l}\text { Reconhecer o estado de incerteza presente tanto na governança dos recur- } \\
\text { sos como no conhecimento científico em geral, exigindo abordagens } \\
\text { adaptativas, deliberativas e participativas que incluam diversos saberes. }\end{array}$ \\
\hline $\begin{array}{l}\text { História politica, } \\
\text { cultura e contexto }\end{array}$ & $\begin{array}{l}\text { Pensar a governança da água, energia, alimentos e meio ambiente a partir } \\
\text { da valorizaçáo de determinadas histórias e culturas políticas para que o } \\
\text { nexo náo seja pensado de forma normativa e sim essencialmente adap- } \\
\text { tável e plural. }\end{array}$ \\
\hline
\end{tabular}

Fonte: Elaboração própria com base em Leach et al. (2007). 


\section{Caminhos para a sustentabilidade a partir do Plano de Ação para a Macrometrópole Paulista 2013-2040}

Neste tópico, abordaremos as narrativas presentes no contexto da MMP a partir do Plano de Ação para a Macrometrópole Paulista 2013-2040 (PAM). Estas narrativas podem nos fornecer elementos para compreender os aspectos do enquadramento de governança sugerida pela abordagem CPS para o desafio do nexo água-energia-alimento. É importante deixar claro que não se trata de um estudo aprofundado do PAM. O objetivo aqui é ilustrar a partir dele a potencialidade da perspectiva CPS para discutirmos de forma mais ampla e complexa os desafios da governança dos recursos no contexto da MMP. Entenderemos como narrativas o balanço entre as trajetórias percorridas e as projeçóes para o futuro em um determinado enquadramento que significaram mudanças ou manutençóes de estruturas e práticas em torno da governança dos recursos.

O PAM se constituiu por uma série de açóes coordenadas pela Empresa Paulista de Planejamento Metropolitano S/A (Emplasa) e pelo governo do Estado de São Paulo a partir de 2011, com o objetivo de reunir em publicaçóes as principais propostas para o futuro do estado paulista.

Esse Plano foi elaborado com vistas a construir um futuro em que se mantenha e se amplie o dinamismo econômico, científico, tecnológico e cultural da MMP, garantindo a sustentabilidade ambiental e, sobretudo, a aceleração da mobilidade social e a superação dos graves problemas sociais que ainda afligem parte de sua população. Ele organiza estratégias, projetos e açôes a serem desenvolvidos na MMP para sedimentar as condiçóes necessárias para atingir esse futuro que todos desejamos, explorando as potencialidades existentes e enfrentando os desafios que se antepóem ao processo de desenvolvimento social e economicamente sustentável (EMPLASA, 2014a, p.5).

A partir do trecho acima, assinado por Renato Viégas, Diretor-presidente da EMPLASA à época, podemos notar que a proposta de futuro passa bastante pelo tema da sustentabilidade. Foi um processo longo e que envolveu uma série de secretarias estaduais, atores políticos e eixos de atuação, como mostra a Figura 2. 
Figura 2 - Fluxo de trabalho do PAM 2013-2040

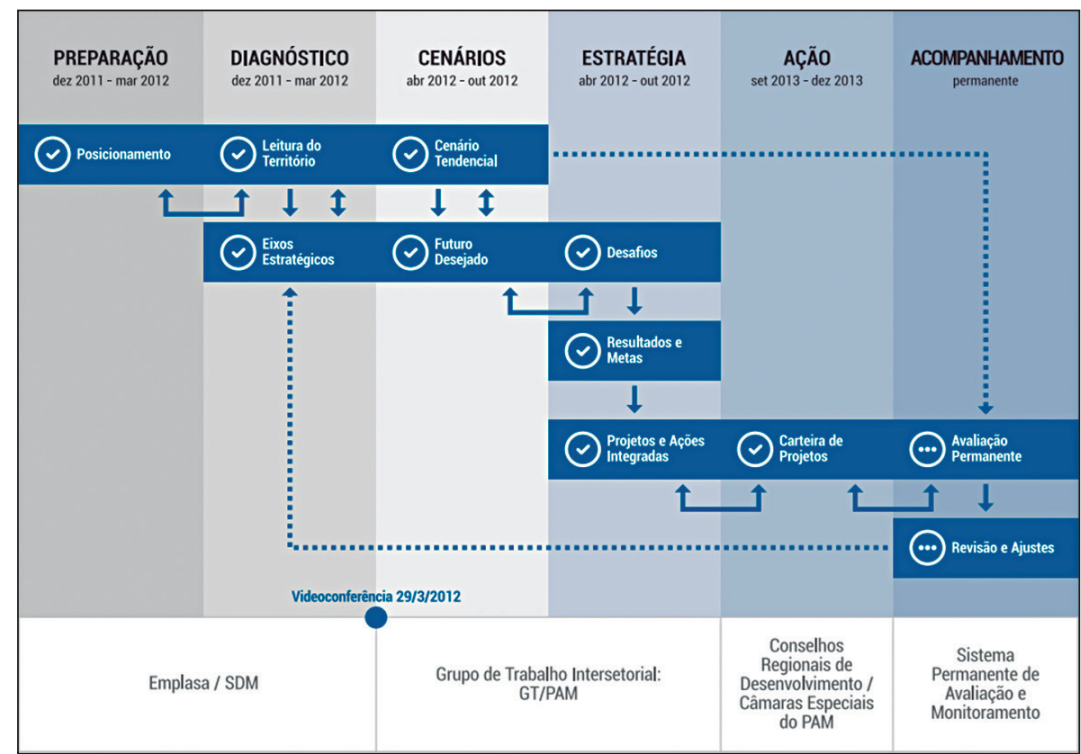

Fonte: EMPLASA (2014a, p.28).

Iremos nos centrar na fase de "açóes", a partir do quarto documento que compóe o PAM, chamado de Carteira de Projetos do PAM (EMPLASA, 2014b). De forma resumida, a etapa de açóes buscou identificar atores (internos e externos ao Governo do Estado de São Paulo), mecanismos de discussão pública e pactos políticos sobre propostas para a viabilização de açóes prioritárias do processo de desenvolvimento da MMP. Esta carteira nasceu a partir de seis seminários regionais. Neles estavam presentes representantes da sociedade civil organizada, dos setores público e privado, da academia, de sindicatos patronais, de secretarias de Estado, além de outros setores. Também envolveram órgãos do governo federal responsáveis pelo planejamento do território e instituições financeiras, tais como o BNDES, a Caixa Econômica e o Banco do Brasil.

Segundo Rovena Negreiros, Diretora de Planejamento da Emplasa à época, o objetivo desta carteira é "articular, de forma sistêmica, açôes e projetos, visando ao pleno desenvolvimento da MMP” (EMPLASA, 2014b, p.7). A escolha de foco para este documento se deu pelo fato de justamente ele ser um dos principais instrumentos que englobam um olhar sistêmico para a MMP. Evidentemente, isto vai de encontro à abordagem de CPS e à própria governança do nexo. Os sistemas foram divididos em "veto- 
res territoriais" e "vetores sistêmicos". Os primeiros são compostos por: Vetor de Desenvolvimento Região Metropolitana de São Paulo; Vetor de Desenvolvimento Bandeirantes; Vetor de Desenvolvimento Vale do Paraíba; Vetor de Desenvolvimento Caminho do Mar; Vetor de Desenvolvimento Sorocaba; Vetor de Desenvolvimento Perimetral da Macrometrópole. Os "sistêmicos" consideram: Sistema de Energia; Recursos Hídricos e Saneamento; Desenvolvimento Ambiental; Inovação Tecnológica, Qualificação da Mão de Obra e Gestão Fiscal; Desenvolvimento Habitacional.

Com atenção aos "vetores sistêmicos", pode-se inferir que três estão diretamente ligados à governança da água, energia e alimentos, são eles: Sistema de Energia; Recursos Hídricos e Saneamento; e Desenvolvimento Ambiental. Quanto ao primeiro, notou-se que as açóes estão em consonância com o Plano Paulista de Energia (PPE). De acordo com a Emplasa (2014b), alguns dos projetos estruturantes são: investimento em tecnologia, abrangendo os biocombustíveis, etanol de segunda geração e o biodiesel de cana-de-açúcar; obrigatoriedade da instalação de aquecedores solares térmicos, células fotovoltaicas e microgeradores eólicos em locais de uso comum de todos os conjuntos habitacionais financiados com recursos públicos; e adoção de medidas para elevar a eficiência energética.

Depreende-se que as açóes estão bastante centradas em argumentos econômicos, tais como eficiência, investimento, leilóes e financiamento. Isto, evidentemente, não é um problema, visto que o Estado de São Paulo é o principal consumidor de energia no país (EMPLASA, 2014b), o que demanda uma constante busca por estruturação da economia voltada ao setor energético. A parte interessante é que há uma forte predisposição ao investimento de tecnologias para energias renováveis. Dentre elas, os biocombustíveis, tais como o etanol e o biodiesel. Aqui nota-se uma forte correlaçáo entre os setores de energia e de agricultura no PAM, pois, atualmente, o biodiesel é majoritariamente produzido a partir do sebo bovino, e uma das alternativas apresentadas pelo PAM é o fortalecimento da agricultura familiar, expandindo, por exemplo, a área agricultável para ampliação do leque de oleaginosas. Outro componente entre energia e água é a preocupação com a utilização de óleos vegetais usados, pois cada litro de óleo descartado incorretamente pode chegar a contaminar 25 mil litros de água.

Em relação aos sistemas hídricos e saneamento e de desenvolvimento ambiental no contexto da MMP, o PAM apresenta as figuras 3 e 4, que sintetizam os principais projetos em questão. 
Figura 3 - Projetos do vetor sistêmico de recursos hídricos e saneamento

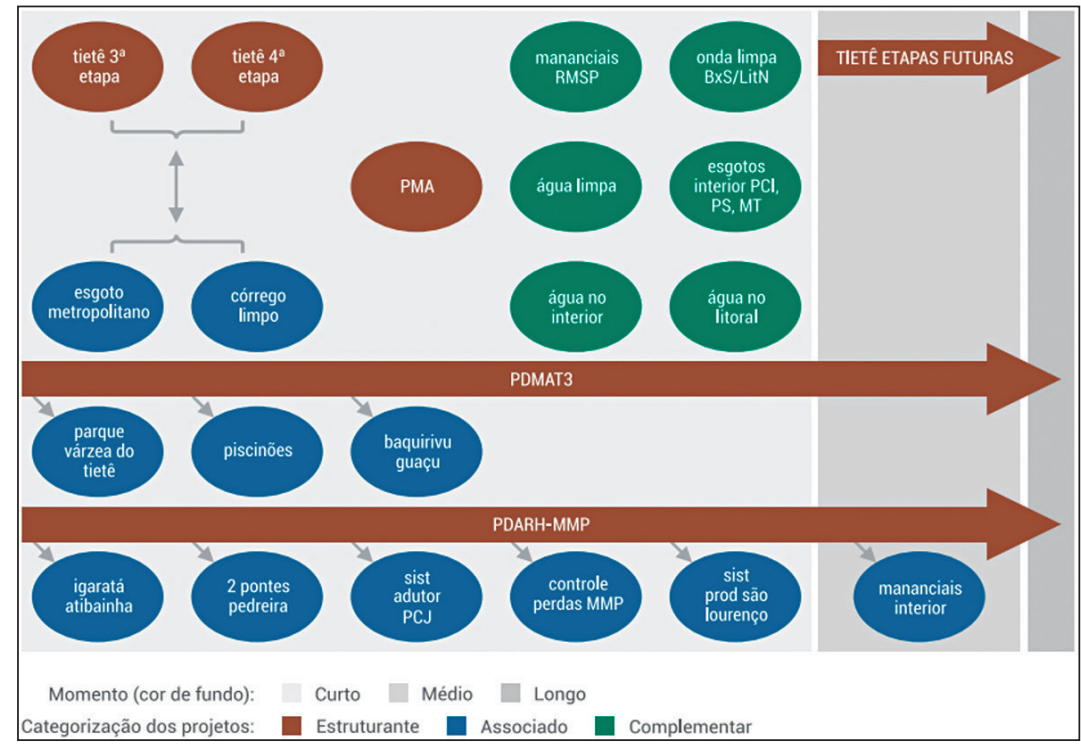

Fonte: EMPLASA (2014b, p.153).

Observa-se que na Figura 3 há três vetores estruturantes. Primeiro, ações ligadas ao Projeto Tietê, que visam universalizar os sistemas de coleta e tratamento de esgotos na Região Metropolitana de Sáo Paulo (RMSP). Segundo, o Plano Diretor de Macrodrenagem (PDMAT), que visa controlar o problema das cheias e da drenagem urbana, tendo como um dos objetivos o compartilhamento da infraestrutura hídrica que, além de buscar tratar das inundaçóes, abre espaço para consórcios com abastecimento de água, geração de energia, entre outros. E terceiro, o Plano Diretor de Aproveitamento de Recursos Hídricos para a Macrometrópole (PDARH-MMP), que considera ser possível aumentar a disponibilidade hídrica para as bacias dos rios Piracicaba, Capivari e Jundiaí (PCJ) de forma a não reduzir a transferência de águas para a RMSP (ao aproveitar as águas do reservatório do Rio Jaguari, pertencente à Companhia Energética de São Paulo [Cesp]). No entanto, náo contextualiza para os leitores quais seriam os gastos energéticos destas transferências e outros possíveis impactos - ou diminuição deles - em termos ambientais. Por outro lado, em consonância com o debate sobre o nexo, o argumento mais geral do PDARH-MMP se baseia na necessidade de soluçóes integradas e multissetoriais.

$\mathrm{Na}$ Figura 4 estão os vetores estruturantes do sistema de desenvolvimento ambiental. Eles estão divididos em: instrumentos de gestáo ambiental, 
Guarapiranga Sustentável, Mata Ciliares e ICMS Ecológico. Os componentes do plano, neste caso, estáo bastante alinhados com a Política Estadual de Mudanças Climáticas (PEMC/2009), a partir de projetos como Programa de Remanescentes Florestais, Plano de Transportes Sustentáveis e Linha Economia Verde. Depreende-se da Figura 4 que o fortalecimento da agricultura familiar e a proteção agroambiental também aparecem como projetos associados e complementares, respectivamente. Este é um ponto importante do PAM, pois há inúmeros trade-offs em relação aos alimentos na região da MPP, principalmente em áreas mais vulneráveis. Como mostraram Giatti et al. (2019), em regióes periféricas de grandes centros como a Região Metropolitana de São Paulo, os moradores muitas vezes precisam se deslocar grandes distâncias para comprar alimentos frescos e saudáveis e, por isso, acabam optando por alimentos ultraprocessados pela praticidade e preços mais acessíveis. Na maioria das vezes, são os únicos alimentos disponíveis em comércios locais. O fortalecimento da produção local de alimentos é uma questão chave que ajudaria a evitar esse ciclo do que vem sendo chamado de "deserto alimentar" nas periferias (CUMMINS; MACINTYRE, 2002).

Além disso, neste tópico do PAM, encontram-se esforços em compreender os ativos ambientais da MMP, bem como os "estresses dos ecossistemas", a fim de garantir um olhar sistêmico para a qualidade ambiental e de vida dos moradores.

Figura 4 - Projetos do vetor sistêmico de desenvolvimento ambiental

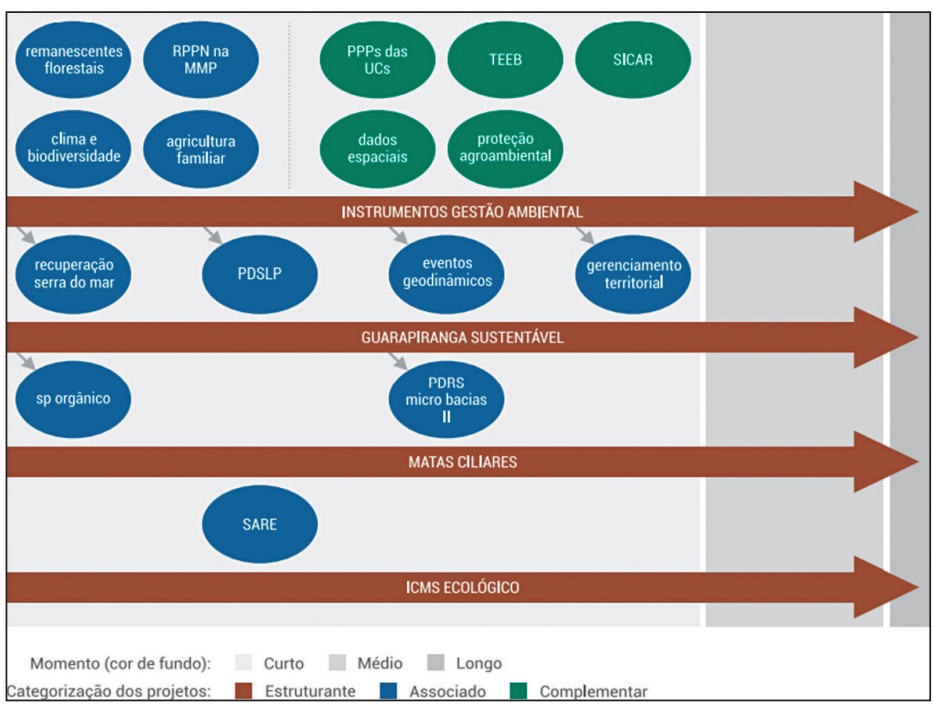

Fonte: EMPLASA (2014b, p.155). 
A partir das discussóes públicas que compuseram a carteira, os projetos passaram por um processo de definição de objetivos, hierarquização, sequenciamento e precificação. Especificamente em relaçáo àqueles que discutimos aqui, os vetores sistêmicos de recursos hídricos e saneamento e o desenvolvimento ambiental foram somente classificados e sequenciados, não tendo sido analisados à luz da hierarquização. Já o de sistema de energia, não passou por nenhum desses processos. A hierarquização foi estipulada a partir de uma análise multicritério. Os objetivos estratégicos foram pautados pelos seguintes graus de contribuição de determinado projeto: visando o aumento da competitividade do território de um vetor; visando a melhoria da conectividade do território do vetor; para a coesão territorial do vetor; e para a sustentabilidade ambiental do território do vetor. Além disso, foram considerados critérios de factibilidade, tais como: financiabilidade, aspectos jurídicos e institucionais, implementação e gestão e viabilidade política.

Se por um lado estas açóes consideram a interdependência entre projetos em andamento no contexto da MMP, a partir de olhares sistêmicos que estão alinhados com o que o conceito de nexo propóe, por outro, assim como mostraram Gonçalves et al. (2020), o PAM pode ser considerado como um instrumento fortemente marcado por um olhar desenvolvimentista (a partir de parcerias público-privadas) e parcerias sócio-privadas que visam o pagamento de serviços ambientais. No entanto, em acordo com esses autores, reiteramos que neste plano há poucos instrumentos para uma gestáo participativa que envolva atores sociais que não detenham conhecimentos técnicos.

Analisando do ponto de vista da abordagem de caminhos para a sustentabilidade, pode-se dizer que o PAM foi construído de maneira coletiva, garantindo que os temas ambientais fossem observados através de diferentes camadas que se sobrepóem. Contudo, o apelo da abordagem para abrir (open up) as políticas às incertezas e à incompletude da própria formação de conhecimento são questóes que precisariam ter mais espaço.

A Empresa Paulista de Planejamento Metropolitano S/A (Emplasa) foi o principal aparato institucional que esteve a frente da busca por uma governança metropolitana no Estado de São Paulo desde a década de 1970. No entanto, em junho de 2019, foi aprovada a sua extinção na Assembleia Estadual de São Paulo por meio da Lei no 17.056/2019. Desde então, foi instituída pelo governo de João Doria a Secretaria Estadual de Desenvolvimento Regional (SEDR), que buscou organizar dentro da pasta atividades em andamento, por exemplo, os Planos de Desenvolvimento Urbano Integrado (PDUI) das regióes metropolitanas do Estado. Além disso, algumas novas iniciativas foram implementadas nos 
últimos anos, tais como os programas "Cidades inteligentes", "Parcerias municipais" e "Canal direto SP + Perto". Elas prometem se basear em novas tecnologias para mudar o jeito de governar, gerar economia e eficiência para o Estado, padronizar procedimentos, melhorar a execução de políticas em cada cidade, entre outros. Contudo, fica aqui o questionamento se estas ferramentas buscam transformar os imaginários da governança macrometropolitana, ampliando formas de democratização do conhecimento ou se são meramente retóricas. Do nosso ponto de vista, a extinção da Emplasa traz inúmeras incertezas ao processo de governança macrometropolitana e ainda não se vê uma estruturação próxima à da Emplasa na SEDR. Podemos inferir que, na articulação com a base teórica deste artigo, há um desencontro evidente com a abordagem CPS, pois ao contrário de ampliar de forma transparente a dinâmica de formação de conhecimento e compromissos, privilegiou a "redução" (close down) destes em favorecimento de interesses vigentes e grupos com maior poder no governo do Estado de São Paulo.

No Quadro 2, buscamos organizar as principais narrativas encontradas no PAM que dialogam com a governança da água, da energia e de alimentos a partir do enquadramento a proposto pela abordagem de CPS.

Quadro 2 - A governança do nexo na MMP a partir do PAM 2013-2040

\begin{tabular}{|c|l|}
\hline Eixo & \multicolumn{1}{c|}{ PAM 2013-2040 } \\
\hline \multirow{5}{*}{$\begin{array}{c}\text { Entidades políticas } \\
\text { e espaços }\end{array}$} & - Conselhos regionais de desenvolvimento e câmaras especiais do \\
& PAM. Entre as entidades estão: EMPLASA; Governo do Estado de \\
& São Paulo; Secretaria Estadual de Saneamento e Recursos Hídricos; \\
& Secretaria Estadual de Energia; Secretaria Estadual de Logística e \\
& Transportes; Secretaria Estadual do Meio Ambiente; Sabesp; Daee; \\
& DER; e Daesp. A carteira de projetos do PAM foi estruturada em "vetores ter- \\
& ritoriais" (Vetor de Desenvolvimento Região Metropolitana de \\
& São Paulo; Vetor de Desenvolvimento Bandeirantes; Vetor de \\
& Desenvolvimento Vale do Paraíba; Vetor de Desenvolvimento \\
& Caminho do Mar; Vetor de Desenvolvimento Sorocaba; Vetor de \\
& Desenvolvimento Perimetral da Macrometrópole). \\
\hline
\end{tabular}




\begin{tabular}{|c|c|}
\hline Eixo & PAM 2013-2040 \\
\hline Estruturação e prática & $\begin{array}{l}\text { - A estruturaçáa considera os chamados "vetores sistêmicos" } \\
\text { de Recursos Hídricos e Saneamento, Sistema de Energia e } \\
\text { Desenvolvimento Ambiental. Os projetos considerados como } \\
\text { estruturantes nesses vetores são: Projeto Tietê (terceira e quar- } \\
\text { ta etapas e etapas futuras), Plano Diretor de Aproveitamento de } \\
\text { Recursos Hídricos para a MMP (PDARH/MMP), Terceiro Plano } \\
\text { Diretor de Macrodrenagem da Bacia do Alto Tietê (PDMAT 3), } \\
\text { Programa Metropolitano de Água 2014-2020 (PMA), Plano Paulista } \\
\text { de Energia } 2020 \text { (PPE), Guarapiranga sustentável, Programa de } \\
\text { Incentivos à Recuperação de Matas Ciliares e ICMS ecológico. } \\
\text { - As práticas dizem respeito a diferentes fases para a construçấo de } \\
\text { uma carteira de projetos: i) workshop para capacitação, ii) hierarqui- } \\
\text { zação de projetos, iii) encadeamento lógico de projetos e iv) docu- } \\
\text { mentaçáo dos processos e resultados. }\end{array}$ \\
\hline Poder e conhecimento & $\begin{array}{l}\text { - O processo de hierarquizaçáo considerou que o Vetor Bandeirantes } \\
\text { (ligação de São Paulo, Jundiaí, Campinas, Rio Claro e Piracicaba) } \\
\text { teve maior importância estratégica, enquanto o Vetor Vale do Paraíba } \\
\text { (ligação entre São Paulo, São José dos Campos e Taubaté) teve } \\
\text { menor relevância. } \\
\text { - Houve um interessante esforço de trabalho em grupo intersetorial. } \\
\text { No entanto, a construçáo de conhecimentos foi bastante pautada por } \\
\text { conhecimento técnico e estratégico, com a ausência de atores não- } \\
\text {-técnicos na formulaçáo do documento. Apesar dos esforços de uma } \\
\text { governança mais integrada e sustentável, o PAM apresenta fortes } \\
\text { componentes orientados aos aspectos competitivos e econômicos } \\
\text { da regiaao. }\end{array}$ \\
\hline Lidar com a incerteza & $\begin{array}{l}\text { - No que diz respeito ao vetor sistêmico hídrico e de saneamento, } \\
\text { pode-se afirmar que o PAM considerou os riscos e incertezas de } \\
\text { dependência do Sistema Cantareira para garantir o abastecimento } \\
\text { para a RMSP. } \\
\text { - No sistema de energia, há incertezas em relação a novos "apagóes" } \\
\text { que possam ocorrer devido a desequilíbrios no sistema hidrelétrico } \\
\text { do país. } \\
\text { - O PAM também identifica que é preciso criar novas sinergias entre } \\
\text { o setor público e o privado, para diminuir riscos nos financiamentos } \\
\text { e investimentos em projetos. } \\
\text { - Além disso, os principais desafios que entram no espectro das } \\
\text { incertezas são: problemas de conectividade territorial, garantir que } \\
\text { a MMP seja uma plataforma de políticas públicas, projetos e açôes } \\
\text { compartilhadas, urbanização inclusiva, definir pactos com diferentes } \\
\text { níveis de governo e setores privados. }\end{array}$ \\
\hline
\end{tabular}




\begin{tabular}{|l|l|}
\hline \multicolumn{1}{|c|}{ Eixo } & \multicolumn{1}{c|}{ PAM 2013-2040 } \\
\hline \multirow{4}{*}{$\begin{array}{l}\text { História política, } \\
\text { cultura e contexto }\end{array}$} & $\begin{array}{l}\text { - A MMP é o espaço urbano mais amplo e complexo do país em } \\
\text { termos demográficos e econômicos. Concentra 174 municípios, por } \\
\text { volta de 33 milhóes de habitantes em um raio de aproximadamente } \\
\text { - } 200 \text { quilômetros do município de Sáo Paulo. } \\
\text { - O planejamento macrometropolitano é relativamente recente e } \\
\text { as açóes dos municípios que a compóem náo eram objeto de pla- } \\
\text { nejamento, sendo pouco integradas e pautadas por racionalidades } \\
\text { setoriais (TAVARES, 2018). } \\
\text { - Há uma grande parte da população (aproximadamente 2,68 } \\
\text { milhóes) vivendo em situaçáo precária e de vulnerabilidade social e } \\
\text { ambiental (CANIL; LAMPIS; SANTOS, 2020). }\end{array}$ \\
\hline
\end{tabular}

Fonte: Elaboração própria com base no PAM 2013-2040.

\section{Considerações finais}

O PAM é o principal instrumento de governança integrativa e multinível até hoje pensado para a MMP. Sem dúvidas, foi um grande avanço para entender as complexidades e os desafios do território e buscar soluções a partir de projetos já em andamento. Entre essas complexidades estão a superação de disputas regionais, de visôes setoriais do planejamento e nas açóes e da falta de integração de políticas e projetos. Principalmente em relação à governança hídrica e de saneamento, energética e de desenvolvimento ambiental. Apesar de a governança dos alimentos náo ser um vetor sistêmico e nem aparecer como um elemento estruturante do plano, a agricultura aparece conectada dentro dos outros sistemas. No entanto, acreditamos que a governança integrada dos setores alimentares é um gargalo em grandes áreas urbanas, principalmente quando se trata de regióes periféricas e vulneráveis. Nesse contexto, é possível afirmar que se podemos encontrar uma perspectiva amigável ao nexo no PAM, ela esteve bastante marcada por um olhar estratégico e técnico, deixando a desejar ao náo considerar experiências humanas de atores mais vulneráveis em relação ao acesso aos recursos no contexto macrometropolitano.

Cabe reconhecer que os setores de água, energia e alimentos já possuem estabelecidas suas próprias estruturas de governança, operando dentro de seus próprios desafios de busca por melhor governança com envolvimento de diversos atores de forma mais inclusiva e democrática. De fato, isto aponta para uma 
elevada complexidade na tentativa de se concretizar algo como uma estrutura de supra-governança, mas que provavelmente seria completamente dificultoso ou até mesmo inviável. Por outro lado, pode ser mais realizável conceber plataformas de múltiplos envolvimentos de instituiçôes e atores - de diferentes setores - com o intuito de encontrar alternativas não prescritivas, mas que possibilitem acoplamentos e sinergias associadas aos recursos. Ou seja, possibilidades de ganhos convergentes e que atenuem trade-offs, que por sua vez possam ser devidamente pactuadas de forma transcendente através de setores e de múltiplas escalas territoriais. Observamos que o PAM apresenta um interessante nível de sofisticação em termos de abordagem sistêmica para o amplo território da macrometrópole, mas efetivamente, é preciso desenvolver melhor um conhecimento aplicável e colaborativo entre múltiplos atores e instituiçóes para obtermos maior êxito na perspectiva do nexo, enquanto um caminho para a sustentabilidade.

Neste artigo, a abordagem de caminhos para a sustentabilidade colaborou na organização dos principais temas a serem considerados no processo de governança do nexo ao sugerir a compreensão das principais entidades políticas e espaços, estruturação e práticas da governança, dimensôes de poder e conhecimento, incertezas no processo e a história política e cultural da MMP. Evidentemente, este é um estudo que não se esgota aqui, pois, após a extinção da Emplasa no ano de 2019, o cenário mudou abruptamente. Isto, além de caminhar na direção oposto ao que a abordagem CPS sugere, demonstra um retrocesso institucional. Ao que se verifica, ela está associada a uma ascensão de poder vinculado ao pensamento neoliberal de simplificação e redução da máquina do Estado. Por outro lado, arguimos que a complexidade deste sistema macrometropolitano e de seus complexos desafios para a sustentabilidade requer, de fato, sofisticação institucional e diálogos ampliados com toda a sociedade.

Ao fim e ao cabo, outros estudos mais aprofundados serão necessários para fornecer novas perspectivas sobre a governança dos recursos na macrometrópole. Por ora, ficam inúmeras dúvidas sobre o futuro da governança e das açóes planejadas no PAM 2013-2040.

\section{REFERÊNCIAS}

ALLOUCHE, J.; MIDDLETON, C.; GYAWALI, D. Technical Veil, Hidden Politics: Interrogating the Power Linkages behind the Nexus. Water Alternatives, Montpellier, v. 8, n. 1, p. 610-626, 2015. Disponível em: https://www.water-alternatives.org/ index.php/alldoc/articles/vol8/v8issue1/277-a8-1-1/file. Acesso em: 08 mar. 2021. 
ALVES, A. J. A revisão da bibliografia em teses e dissertaçóes: meus tipos inesquecíveis. Cadernos de Pesquisa, Sáo Paulo, n. 81, p. 53-60, 1992. Disponível em: http://publicacoes.fcc.org.br/index.php/cp/article/view/990. Acesso em: 08 mar. 2021.

AMARAL, M. H. et al. Environmental injustices on green and blue infrastructure: Urban nexus in a macrometropolitan territory. Journal of Cleaner Production, Amsterdam, v. 289, 2021. Disponível em: https://doi.org/10.1016/j.jclepro.2021.12 5829. Acesso em: 27 mar. 2021.

ARTIOLI, F.; ACUTO, M.; McARTHUR, J. The water-energy-food nexus: an integration agenda and implications for urban governance. Political Geography, Oxford, v.61, p.215-223, 2017. Supplement C. Disponível em: https://doi. org/10.1016/j.polgeo.2017.08.009. Acesso em: 27 mar. 2021.

BENITES-LAZARO, L. L. et al. Land-water-food nexus of biofuels: Discourse and policy debates in Brazil. Environmental Development, Amsterdam, v. 33, 2020. Disponível em: https://doi.org/10.1016/j.envdev.2019.100491. Acesso em: 27 mar. 2021.

CAIRNS, R.; KRZYWOSZYNSKA, A. Anatomy of a buzzword: the emergence of 'the water-energy-food nexus' in UK natural resource debates. Environmental Science \& Policy, New York, v. 64, p.164-170, 2016. Disponível em: https://doi. org/10.1016/j.envsci.2016.07.007. Acesso em: 28 mar. 2021.

CANIL, K.; LAMPIS, A.; SANTOS, K. L. dos. Vulnerabilidade e a construção social do risco: uma contribuição para o planejamento na macrometrópole paulista. Cadernos Metrópole, São Paulo, v. 22, n. 48, 2020. Disponível em: http://dx.doi. org/10.1590/2236-9996.2020-4803. Acesso em: 28 mar. 2021.

COLLINGRIDGE, D. The social control of technology. London: Frances Pinter, 1980.

COVARRUBIAS, M. The nexus between water, energy and food in cities: towards conceptualizing socio-material interconnections. Sustainability Science, Tokyo, v. 14, n. 2, p. 277-287, mar. 2019.

CUMMINS, S; MACINTYRE, S. Food deserts: evidence and assumption in health policy making. BMJ, London, v. 325, p. 436-438, 2002.

DALLA FONTANA, M. et al. The water-energy-food nexus research in the Brazilian context: What are we missing? Environmental Science \& Policy, New York, v. 112, p. 172-180, 2020. Disponível em: https://doi.org/10.1016/j.envsci.2020.06.021. Acesso em: 29 mar. 2021. 
EMPLASA. Plano de Ação da Macrometrópole Paulista 2013-2040: Política de Desenvolvimento da Macrometrópole. São Paulo: Emplasa, 2014a. Disponível em: https://bibliotecavirtual.sdr.sp.gov.br/AbrirArquivo.aspx?ID=20358. Acesso em: 18 jan. 2022.

EMPLASA. Plano de Açáo da Macrometrópole Paulista 2013-2040: Carteira de Projetos do PAM. São Paulo: Emplasa, 2014 b.

GIATTI, L. L. Participatory Research in the Post-Normal Age: Unsustainability and Uncertainties to Rethink Paulo Freire's Pedagogy of the Oppressed. Zurich: Springer International Publishing, 2019.

GIATTI, L. L. et al. Nexos de exclusão e desafios de sustentabilidade e saúde em uma periferia urbana no Brasil. Cadernos de Saúde Pública, Rio de Janeiro, v. 35, n. 7, 2019. Disponível em: https://www.scielo.br/j/csp/a/VzMkzg3YK9DsdyfZg4ZTgjS/?1 ang=pt. Acesso em: 18 jan. 2022.

GONÇALVES, L et al. O litoral da macrometrópole: tão longe de Deus e tão perto do Diabo. Desenvolvimento e Meio Ambiente, Curitiba, v. 54, p. 40-65, 2020. Disponível em: http://dx.doi.org/10.5380/dma.v54i0.69275. Acesso em: 29 mar. 2021.

JACOBI, P. R.; CIBIM, J.; LEAO, R. de S. Crise hídrica na Macrometrópole Paulista e respostas da sociedade civil. Estudos Avançados, São Paulo, v. 29, n. 84, p. 27-42, 2015. Disponível em: http://www.scielo.br/scielo.php?script=sci_arttext\&pid=S0103$40142015000200027 \& \operatorname{lng}=$ en\&nrm=iso. Acesso em: 18 jun. 2020.

JASANOFF, S. Technologies of Humility: Citizen Participation in Governing Science. Minerva, Dordrecht, v. 41, n. 3, p. 223-244, 2003. Disponível em: https:// doi.org/10.1023/A:1025557512320. Acesso em: 29 mar. 2021.

KHONDKER, H. Glocalization as Globalization: Evolution of a Sociological Concept. Bangladesh e-Journal of Sociology, Dhaka, v. 1, n. 2, 2004.

KURIAN, M. The water-energy-food nexus Trade-offs, thresholds and transdisciplinary approaches to sustainable development. Environmental Science \& Policy, New York, v. 68, p. 97-106, 2017.

KURIAN, M. et al. Governance of Water-Energy-Food Nexus: A Social Network Analysis Approach to Understanding Agency Behaviour. In: HÜLSMANN, S.; ARDAKANIAN, R. (ed.). Managing Water, Soil and Waste Resources to Achieve Sustainable Development Goals: Monitoring and Implementation of Integrated Resources Management. Cham: Springer International Publishing, 2018. p. 125-147. 
LEACH, M.; SCOONES, I.; STIRLING, A. Governing epidemics in an age of complexity: Narratives, politics and pathways to sustainability. Global Environmental Change, Oxford, v. 20, n. 3, p. 369-377, 2010.

LEACH, M.; SCOONES, I.; STIRLING, A. Pathways to Sustainability: an overview of the STEPS Centre approach. STEPS Approach Paper, Brighton, 2007. Disponível em: https://steps-centre.org/wp-content/uploads/final_steps_overview.pdf. Acesso em: 18 jan. 2022.

LEACH, M. et al. Understanding Governance: pathways to sustainability. STEPS Working Paper 2, Brighton, 2007. Disponível em: https://steps-centre.org/wp-content/ uploads/final_steps_governance.pdf. Acesso em: 18 jan. 2022.

LEICHENKO, R.; SOLECKI, W. Climate change in suburbs: An exploration of key impacts and vulnerabilities. Urban Climate, Amsterdam, v. 6, p. 82-97, 2013.

RASUL, G.; SHARMA, B. The nexus approach to water-energy-food security: an option for adaptation to climate change. Climate Policy, Oxford, v. 16, n. 6, p. 682-702, 2016.

STIRLING, A. Developing 'Nexus Capabilities': towards transdisciplinary methodologies. Brighton: SPRU - Science Policy Research Unit, 2015. Discussion Paper.

STIRLING, A. Keep it complex. Nature, London, v. 468, n. 7327, p. 1029-1031, 2010 .

TAVARES, J. Formação da macrometrópole no Brasil: Construção teórica e conceitual de uma regiáo de planejamento. EURE, Santiago, v. 44, n.133, p. 115134, 2018. Disponível em: http://dx.doi.org/10.4067/s0250-71612018000300115. Acesso em: 29 mar. 2021.

TORRES, P. H. C.; RAMOS, R. F.; GONÇALVES, L. R. Conflitos ambientais na Macrometrópole Paulista: Paranapiacaba e São Sebastião. Ambiente \& Sociedade, São Paulo, v. 22, e0101, 2019. Disponível em: https://doi.org/10.1590/18094422asoc20190101vu2019l2ao. Acesso em: 29 mar. 2021.

TORRES, P. H. C; RAMOS, R. F.; POLLACHI, A. A macrometropolização em São Paulo: reterritorialização, reescalonamento e a cidade-região. Cadernos Metrópole, São Paulo, v. 22, n. 47, p. 103-122, 2020. Disponível em: https://www.scielo.br/j/ cm/a/XJXvyShTMg6JQxTsQ34tfkp/abstract/?lang=pt. Acesso em: 29 mar. 2021.

URBINATTI, A. M.; FERREIRA, L. DA C. As políticas climáticas e seus desafios em megacidades. Ideias, Campinas, v. 10, p. e019001, 12 ago. 2019. Disponível em: 
https://periodicos.sbu.unicamp.br/ojs/index.php/ideias/article/view/8656195. Acesso em: 29 mar. 2021.

URBINATTI, A. M. et al. The conceptual basis of water-energy-food nexus governance: systematic literature review using network and discourse analysis. Journal of Integrative Environmental Sciences, Oxfordshire, v. 17, n. 2, 2020a. Disponível em: https://doi.org/10.1080/1943815X.2020.1749086. Acesso em: 29 mar. 2021.

URBINATTI, A. M. et al. 'Opening up' the governance of water-energy-food nexus: Towards a science-policy-society interface based on hybridity and humility. Science of The Total Environment, Amsterdam, v. 744, 2020b. Disponível em: https://doi. org/10.1016/j.scitotenv.2020.140945. Acesso em: 29 mar. 2021.

WAHL, D.; NESS, B.; WAMSLER, C. Implementing the urban food-water-energy nexus through urban laboratories: A systematic literature review. Sustainability Science, Tokyo, v. 16, p. 663-676, 2021. Disponível em: https://link.springer.com/ article/10.1007/s11625-020-00893-9. Acesso em: 29 mar. 2021.

WEITZ, N. et al. Closing the Governance Gaps in the Water-Energy-Food Nexus: Insights from Integrative Governance. Global Environmental Change, Oxford, v. 45, p. 165-173, 2017. Disponível em: https://doi.org/10.1016/j.gloenvcha.2017.06.006. Acesso em: 29 mar. 2021.

WYNNE, B. Uncertainty and environmental learning: Reconceiving science and policy in the preventive paradigm. Global Environmental Change, Oxford, v. 2, n. 2, p. 111-127, 1992. Disponível em: http://tbauler.pbworks.com/w/file/ fetch/48548191/Wynne_uncertainty\%20and\%20enviornmental\%20learning.pdf. Acesso em 29 mar. 2021.

Recebido em: 30 de março de 2021

Aprovado em: 25 de agosto de 2021 